\title{
ATIVIDADE EDUCATIVA PARA A PROMOÇÃO DO CUIDADO COM O RECÉM-NASCIDO
}

Suianny Christina Soares Santos Ribeiro

Enfermeira, Especialista em Saúde da Família, Prefeitura Municipal de Mombaça. Mombaça (CE), Brasil.

\section{Rebeca Silveira Rocha}

Enfermeira, Doutora em Enfermagem, Docente do Centro Universitário Estácio do Ceará. Fortaleza (CE), Brasil.

\section{Lia Maristela da Silva Jacob}

Enfermeira, Doutoranda em Ciências da Saúde, Universidade Estadual de Campinas. Campinas (SP), Brasil.

\section{Herla Maria Furtado Jorge}

Enfermeira, Doutora em Tocoginecologia. Docente da Universidade Federal do Piauí. Teresina (PI), Brasil.

\section{Reginaldo Roque Mafetoni}

Enfermeiro, Doutorado em Ciências da Saúde. Universidade Estadual de Campinas. Campinas (SP), Brasil.

\section{Cláudia Jeane Lopes Pimenta}

Enfermeira, Mestranda do Programa de Pós-Graduação em Enfermagem, Universidade Federal da Paraíba. João Pessoa (PB), Brasil.
RESUMO: O presente estudo buscou avaliar a influência de uma atividade educativa para a promoção do cuidado com o recém-nascido. Trata-se de um estudo exploratório, descritivo e quantitativo, realizado no Alojamento Conjunto de uma maternidade em Mombaça-CE, com 61 puérperas. Para coleta de dados, utilizaram-se da observação informal e de um questionário adaptado, em que foram registrados as informações pessoais e os dados sobre os cuidados com o recém-nascido e aleitamento materno pré e pós-atividade educativa, para avaliar as principais dificuldades das puérperas. Uma parte relevante das mulheres apresentava conhecimentos errôneos sobre os cuidados com o recém-nascido e sobre o aleitamento materno. A realização da atividade educativa proporcionou a orientação adequada das mulheres e o esclarecimento de dúvidas existentes. Assim, torna-se necessária a prática constante de educação em saúde às gestantes e puérperas, tanto na assistência pré-natal como na Unidade de Alojamento Conjunto, associado à distribuição de material educativo de fácil compreensão.

PALAVRAS-CHAVE: Educação em saúde; Aleitamento materno; Cuidado do lactente.

\section{EDUCATIONAL ACTIVITY FOR THE PROMOTION OF CARE WITH THE NEWLY BORN}

ABSTRACT: The influence of educational activities in the promotion of care for the newly born child is evaluated through an exploratory, descriptive and quantitative study in a maternity hostel in Mombaça CE Brazil, with 61 puerperas. Data collection comprised informal observation and a questionnaire in which personal information and data on care with the newly born child and pre- and post-educational breast-feeding were registered to evaluate the main difficulties of puerperas. Several mothers had mistaken knowledge on care with newly born children and on breast-feeding. Educational activity provided the proper guidelines and the elimination of doubts. The constant practice of health care to pregnant women and puerperas in pre-natal visits associated with the distribution of easy education material is highly relevant.

KEY WORDS: Health education; Breast feeding; Infant Care. 
Nos dias atuais evidencia-se o forte enfoque que o caráter reprodutivo recebe ao cenário de atenção à saúde da mulher, por meio do qual a gestação, o parto e o cuidar de um filho são considerados eventos de singular valor na vida da mulher e no seu processo de crescimento e amadurecimento. Essa importância dada a atenção à saúde materno-infantil pode ser verificada pela crescente conquista de espaço e visibilidade nas políticas nacionais de saúde, dentre as quais podem ser citadas o Programa da Saúde Materno-Infantil (PSMI), criado na década de 70 , com a finalidade de proteção ao binômio mãe-filho; o Programa de Assistência Integral à Saúde da Mulher (PAISM), instituído na década de 80, objetiva a qualidade na atenção à mulher em todas as fases de seu ciclo vital; e o Programa de Humanização no Pré-Natal e Nascimento (PHPN), adotado em 2000, visa melhorar a assistência ao pré-natal, parto e puerpério ${ }^{1-2}$.

Durante o ciclo gravídico-puerperal, a mulher vivencia diversas mudanças biofisiológicas e psicoemocionais, sendo de suma importância o pronto acompanhamento da enfermagem, de forma a proporcionar cuidados integrais, individualizados e humanizados, que viabilizem o conforto e a segurança da mãe e do bebê. É imprescindível a realização de um diálogo atento e de uma interação efetiva, no qual o enfermeiro mostre disponibilidade, interesse e preocupação com a paciente, respeitando sua subjetividade, suas crenças e seus valores $^{3}$.

A literatura ${ }^{1-4}$ tem enfatizado a importância do acompanhamento das mulheres desde o início da gestação até o puerpério, oferecendo apoio e suporte, prestando orientações adequadas sobre os cuidados com o bebê e o autocuidado, além do esclarecimento de dúvidas e anseios, o que poderá proporcionar maior qualidade de vida para a mãe e um crescimento e desenvolvimento saudável para a criança.

A redução da mortalidade infantil é considerada grande indicador do desenvolvimento social e econômico de um país. O período neonatal, de forma mais específica, tem sido destacado como uma das prioridades nas diretrizes políticas de saúde da criança, sendo enfocados os cuidados essenciais com neonatos, incentivos à amamentação, imunizações, nutrição, acompanhamento do crescimento e desenvolvimento infantil e prevenção de acidente 5 .

Estes cuidados justificam a importância de se desenvolver atividades educativas no contexto das unidades de Alojamento Conjunto, para atingir uma assistência de enfermagem integral e de maior qualidade para a mãe e o bebê, bem como contribuir para a diminuição das causas de mortalidade infantil ${ }^{6}$.

Assim, o presente estudo tem como objetivo avaliar o conhecimento das mães sobre os cuidados com o recém-nascido $(\mathrm{RN})$ e o impacto de uma atividade educativa com material específico sobre esses cuidados.

\section{METODOLOGIA}

Trata-se de um estudo exploratório, do tipo descritivo e de natureza quantitativa, realizado no período de agosto de 2012 a junho de 2013 com 61 puérperas que se encontravam no Alojamento Conjunto de uma maternidade de referência do município de Mombaça-CE. O sistema de alojamento conjunto trata-se de um princípio em que o RN sadio deve permanecer ao lado da mãe durante toda a sua estadia em ambiente hospitalar, possibilitando o estabelecimento de laços afetivos entre o binômio mãe-filho e a orientação dos profissionais sobre os cuidados necessários com o RN e o incentivo ao aleitamento materno ${ }^{7}$.

Para coleta de dados, utilizaram-se da observação informal e de um questionário semiestruturado, contendo as seguintes variáveis: idade, número de filhos, número de gestações, escolaridade e renda e questões relacionadas ao cuidado com o recém-nascido, sendo aplicado antes e depois da atividade educativa, a fim de avaliar as principais deficiências das puérperas, e, posteriormente, avaliar as informações adquiridas por meio da intervenção.

Para a atividade educativa foi utilizado um material específico elaborado pelos autores, em forma de álbum seriado e folders, sendo adaptados dos manuais Cuidados do Recém-Nascido, ${ }^{8}$ Aleitamento Materno ${ }^{9}$ e Vale a Pena Crescer em Segurança ${ }^{10}$. Esses materiais foram entregues para as mulheres e, em seguida, foi realizada uma roda de conversa para a discussão de diversos 
aspectos relacionados ao cuidado com o RN e a prática do aleitamento materno.

O estudo foi desenvolvido de acordo com o preconizado pela resolução n ${ }^{0}$ 196/96 do Conselho Nacional de Saúde, sendo aprovado pelo Comitê de Ética em Pesquisa da Faculdade Católica Rainha do Sertão, protocolo $\mathrm{n}^{\mathrm{O}} 20110192$. Os participantes foram devidamente esclarecidos sobre a justificativa da pesquisa, sua finalidade, riscos e benefícios, procedimentos a serem realizados, garantia de sigilo e confidencialidade das informações prestadas e assinaram o Termo de Consentimento Livre e Esclarecido.

\section{RESULTADOS}

Participaram deste estudo 61 puérperas, sendo observada uma média de idade de 27,7 anos, sendo a idade mínima de 16 anos e a máxima de 38 anos. 0 número de filhos variou de um a seis, com média de 2,1 filhos por mulher. As primíparas representaram 37,7\% da amostra e as secundíparas totalizaram $29,5 \%$. Em relação ao nível de escolaridade, $68,9 \%$ das participantes possuíam mais de oito anos de estudo, enquanto 4,9\% eram analfabetas. Foi identificada maior frequência de mulheres com renda superior a um salário mínimo (50,8\%).

$\mathrm{Na}$ Tabela 1 são apresentas as informações sobre os cuidados com o RN após a saída da maternidade, antes da realização da atividade educativa, sendo evidenciado que a maioria das entrevistadas $(52,4 \%)$ referiu que elas próprias cuidariam do bebê. Foi evidenciado que grande parte das puérperas $(62,3 \%)$ afirmou ter recebido orientações sobre os cuidados com o RN durante as consultas de pré-natal e no período em que estavam internadas na unidade de alojamento conjunto.

Quando questionadas sobre a confiança para realização dos cuidados com o bebê, a maioria das mulheres relatou mais segurança para amamentar $(85,2 \%)$, seguido do banho higiene e cuidados com o coto umbilical (70,5\% para ambos). O menor índice apresentado foi em relação à prevenção de acidentes, correspondendo a 47,5\%.

\begin{tabular}{lcc} 
(n=61) & n & $\%$ \\
\hline Variáveis & & \\
\hline Cuidados ao recém-nascido pós-alta & 32 & 52,4 \\
\hline Mãe & 15 & 24,6 \\
Avó & 2 & 3,3 \\
Pai & 12 & 19,7 \\
Babá/cuidadora & & \\
\hline Orientações antes da atividade & 38 & 62,3 \\
\hline Sim & 23 & 37,7 \\
Não & 43 & 70,5 \\
\hline Segurança sobre os cuidados com o recém-nascido & \\
\hline Banho/higiene & 52 & 85,2 \\
Amamentação & 31 & 50,8 \\
Cuidados com a pele & 37 & 60,6 \\
Sono/repouso & 29 & 47,5 \\
Prevenção de acidentes & 43 & 70,5 \\
Cuidados com o coto umbilical & & \\
\hline
\end{tabular}

Fonte: Dados da pesquisa

No que tange ao conhecimento das puérperas sobre o aleitamento materno, percebe-se que todas as mulheres $(100,0 \%)$ concordaram que o leite materno evita doenças, devendo ser introduzidos outros alimentos apenas a partir dos seis meses de vida, sendo importante a criança mamar para produzir mais leite. Todas as entrevistadas também acertaram que o aleitamento materno não causa a flacidez da mama (100,0\%).

$\mathrm{O}$ maior índice de erro foi relacionado à afirmativa sobre o RN poder mamar em outra mulher, em que $39,9 \%$ das puérperas responderam que sim. Outro erro frequente foi sobre a pega correta da aréola, em que 26,2\% disseram que não precisava abocanhar toda a aréola do seio. As afirmativas "É mito o fato de que o RN chora porque o leite da mamada não foi suficiente" e "Antes da mamada é preciso a limpeza do seio" (22,9\% e 21,3\%, respectivamente também obtiveram altas prevalências de erro (Tabela 2).

Tabela 2. Conhecimento das puérperas sobre aleitamento materno antes da realização da atividade educativa, Mombaça-CE, 
2013. $(\mathrm{n}=61)$

\begin{tabular}{|c|c|c|c|c|c|c|}
\hline \multirow{2}{*}{ Aleitamento materno } & \multicolumn{2}{|c|}{ Acertos } & \multicolumn{2}{|c|}{ Erros } & \multicolumn{2}{|c|}{ Desconhecem } \\
\hline & $\mathbf{n}$ & $\%$ & $\mathbf{N}$ & $\%$ & $\mathbf{N}$ & $\%$ \\
\hline A amamentação não faz o seio cair & 61 & 100,0 & - & - & - & - \\
\hline Oferece proteção contra doenças & 61 & 100,0 & - & - & - & - \\
\hline RN deve ditar o horário e duração da mamada & 58 & 95,1 & 3 & 4,9 & - & - \\
\hline $\mathrm{O} 1^{\circ}$ leite é amarelo e fraco, depois fica ralo & 59 & 96,7 & 2 & 3,3 & - & - \\
\hline $\begin{array}{l}\text { Se RN apresenta fezes moles, deve-se suspender a ama- } \\
\text { mentação }\end{array}$ & 43 & 70,5 & - & - & 18 & 29,5 \\
\hline $\begin{array}{l}\text { Leite empedrado - massagens, banho de sol e ordenha } \\
\text { do seio }\end{array}$ & 33 & 54,1 & 11 & 18,0 & 17 & 27,9 \\
\hline RN tomar água ou chá entre as mamadas & 56 & 91,8 & 2 & 3,3 & 3 & 4,9 \\
\hline RN deve abocanhar toda a auréola & 45 & 73,8 & 16 & 26,2 & - & - \\
\hline Antes da mamada é preciso a limpeza do seio & 45 & 73,8 & 13 & 21,3 & 3 & 4,9 \\
\hline $\begin{array}{l}\text { Não deve ocorrer a introdução de outros alimentos nos } \\
\text { primeiros } 6 \text { meses de vida, porque o leite materno é su- } \\
\text { ficiente }\end{array}$ & 61 & 100,0 & - & - & - & - \\
\hline $\begin{array}{l}\text { É mito o fato de que o RN chora porque o leite da mama- } \\
\text { da não foi suficiente }\end{array}$ & 26 & 42,6 & 14 & 22,9 & 21 & 34,5 \\
\hline Quanto mais o bebê mama, mais leite é produzido & 61 & 100,0 & - & - & - & - \\
\hline O RN não pode mamar em outra mulher & 30 & 49,2 & 24 & 39,3 & 7 & 11,5 \\
\hline
\end{tabular}

$\mathrm{Na}$ Tabela 3 é mostrado o conhecimento das puérperas sobre os cuidados gerais com o RN antes da aplicação

da atividade educativa, sendo identificado maior número de acertos. Todas as mulheres (100,0\%) afirmaram corretamente que se deve trocar a fralda e limpar o bebê sempre que necessário; identificar os motivos do choro do RN; o RN não pode ficar sem a supervisão de um adulto em superfícies altas; o RN não pode ficar com crianças menores e que o bebê deve usar roupas adequadas ao clima de sua região geográfica.

O maior índice de erro que ocorreu está relacionado ao uso de álcool a 70\% no coto umbilical, no qual 29,5\% das mulheres relataram não haver necessidade. A informação errônea de que o bebê chora porque o leite está secando também foi referida por uma parcela relevante de mulheres (23,0\%). Também foi evidenciada a necessidade de orientação dos profissionais de saúde quanto ao uso de chupetas e desenvolvimento de doenças na boca, haja vista que $19,7 \%$ disseram que a chupeta não traz problemas ao $\mathrm{RN}$ e outras $47,5 \%$ desconheciam totalmente os malefícios da chupeta.
Tabela 3. Conhecimento das puérperas sobre cuidados gerais com o bebê antes da realização de atividade educativa, 
Mombaça-CE, 2013. $(n=61)$

\begin{tabular}{|c|c|c|c|c|c|c|}
\hline \multirow{2}{*}{ Cuidados com o recém-nascido } & \multicolumn{2}{|c|}{ Acertos } & \multicolumn{2}{|c|}{ Erros } & \multicolumn{2}{|c|}{ Desconhecem } \\
\hline & $\mathbf{n}$ & $\%$ & $\mathbf{n}$ & $\%$ & $\mathbf{n}$ & $\%$ \\
\hline Banhar o RN com produtos de odor forte & 26 & 42,6 & 28 & 45,9 & 7 & 14,5 \\
\hline Troca as fraldas do bebê quando necessário e o lava e seca para evitar assaduras & 61 & 100,0 & - & - & - & - \\
\hline Uso de álcool a $70 \%$ no coto umbilical, sem apertá-lo com fitas ou panos & 32 & 52,5 & 18 & 29,5 & 11 & 18 \\
\hline Se cólicas no RN, dar chá ou água com açúcar & 51 & 83,6 & 6 & 9,8 & 4 & 6,6 \\
\hline Se RN com olhos ou pele amarelados, necessita de banho de sol pela manhã & 53 & 86,9 & 6 & 9,8 & 2 & 3,3 \\
\hline O berço do RN deve ser cheio de panos e cobertores & 53 & 86,9 & 8 & 13,1 & - & - \\
\hline RN apresenta choro na mamada, indica que o leite está secando & 47 & 77,0 & 14 & 23,0 & - & - \\
\hline RN chora por estar com fome, frio, calor, dor, fralda suja ou querendo colo & 61 & 100,0 & - & - & - & - \\
\hline O uso de chupetas traz maior possibilidade de desenvolver sapinho no RN & 20 & 32,8 & 12 & 19,7 & 29 & 47,5 \\
\hline O RN pode ficar em cima de móveis sem supervisão de adulto & 61 & 100,0 & - & - & - & - \\
\hline RN pode ser cuidados por crianças menores sem acompanhamento de um adulto & 61 & 100,0 & - & - & - & - \\
\hline Pode-se usar qualquer fralda desde que o RN não apresente alergia & 61 & 100,0 & - & - & - & - \\
\hline
\end{tabular}

Após serem recolhidos os questionários, realizou-se a atividade educativa com as puérperas que se encontra-

vam no Alojamento Conjunto e, em seguida, foi entregue um material didático com dicas sobre aleitamento materno e cuidados com o RN.

Foi distribuído um novo questionário e $100 \%$ da amostra acertou todos os questionamentos. Ao final da atividade educativa e das entrevistas, foi distribuído um questionário para analisar o conhecimento das mulheres sobre as questões anteriormente investigadas, sendo observado que as participantes acertaram todos os questionamentos. Também foi entregue um instrumento para que as puérperas avaliassem as informações repassadas.

Em relação à avaliação, 50,8\% das puérperas consideraram as atividades como ótima, 44,3\% a classificaram como boa e apenas $4,9 \%$ a classificaram como regular. Toda a amostra $(100,0 \%)$ relatou que as informações repassadas foram importantes para o auxílio no cuidado adequado para com o bebê.

Entre as puérperas entrevistadas, $77,1 \%$ atribuíram a nota 10 para a atividade, enquanto as demais $(22,9 \%)$ avaliaram com nota 9 . Todas as mulheres $(100,0 \%)$ concordaram que seria imprescindível que os profissionais da saúde, sobretudo os enfermeiros, realizassem sessões educativas com maior frequência, buscando auxiliar não somente as primíparas, mas todas as mães a prestar um cuidado adequado e integral ao seu bebê.

\section{DISCUSSÃO}

Neste estudo, observou-se que as puérperas ainda possuem concepções errôneas relacionadas ao aleitamento materno e aos cuidados gerais com o RN, sendo observado que aproximadamente $40 \%$ da amostra relatou não haver problemas em oferecer o seio de outra mulher para o seu filho. O aleitamento materno cruzado é uma prática frequente entre as mães, sobretudo entre as mais jovens, em decorrência das dificuldades para a ordenha do leite e pelo desconhecimento sobre os perigos relacionados $^{11}$. Todavia, essa atividade deve ser evitada, por existir o risco de transmissão vertical de doenças ao recém-nascido ${ }^{12}$.

Nesse sentido, os profissionais de saúde devem orientar as mães acerca da importância de não realizarem a prática do aleitamento cruzado, uma vez que cerca de 65\% das afecções e infecções adquiridas pelo bebê estão relacionadas ao leite materno, dentre elas o HIV, a hepatite C, o HTLV (Vírus Linfotrófico da Célula Humana), o herpes vírus, a rubéola, a tuberculose e a sífilis ${ }^{12-14}$. 
Notou-se também que as mulheres não sabiam como estimular e a maneira correta da pega do mamilo pelo RN, o que pode estar associado ao fato de não haver orientação, no Alojamento Conjunto e na consulta de pré-natal, acerca da maneira correta como o bebê deve abocanhar o mamilo para a produção e descida eficaz do leite. Embora o Programa Nacional de Incentivo ao Aleitamento Materno relate que, entre as mães brasileiras, a orientação sobre a amamentação corresponde a $95 \%$, ainda existem mulheres, principalmente as sem experiência em amamentar, que não sabem as técnicas corretas para tal atividade ${ }^{15}$.

A pega incorreta na hora da mamada, além de contribuir para a sucção inadequada do leite pelo bebê, faz com que este não se alimente o necessário e ainda cause traumas à mama, como a fissura mamilar ${ }^{16}$. O uso de técnicas incorretas pelas participantes, suscita outro erro que ocorreu em uma parcela significativa das entrevistadas: achar que o leite é insuficiente para a saciedade da criança e por esse motivo há o choro do bebê.

Um anseio comum evidenciado entre as mulheres investigadas foi entender que o leite está secando e por isso, o bebê não suga. Este achado é referido na literatura como um percussor do desmame precoce, sendo necessário que o profissional de saúde oriente as mães sobre a demanda de leite para o bebê e a importância de não introduzir outros alimentos durante os primeiros seis meses de vida ${ }^{11}$.

Embora 73\% das mulheres tivessem conhecimentos sobre a higiene adequada da mama antes do aleitamento, algumas participantes relataram que não tinham nenhum preparo para a realização desta atividade, como a limpeza da mama antes de amamentar com pano úmido e limpo, pois, julgaram não haver necessidade. A não higienização das mamas gera riscos para a saúde do RN, como a transmissão de candidíase oral ou monilíase, podendo acarretar sérias complicações para o bebê $\hat{e}^{17}$.

Durante o acompanhamento pré-natal, é necessário que o enfermeiro alerte a mulher sobre esses cuidados básicos, como expor a mama ao sol para evitar ou cicatrizar fissuras, realizar a higiene oral do bebê e ter práticas de higiene ao sair do banheiro (uso de sanitário), além da necessidade de lavar as mãos sempre que entrar em contato com o RN. ${ }^{18}$ Estudo realizado com lactentes que apresentavam o diagnóstico de dermatite atópica em Porto Alegre - RS, ressaltou que a mama não higienizada é fator predisponente para a colonização mucocutânea pelo Staphylococcus aureus, com prevalência de até $90 \%{ }^{19}$.

Quando investigado sobre o conhecimento das puérperas sobre as técnicas para evitar ou tratar o ingurgitamento mamário, 18\% não apresentavam informações sobre este aspecto. Durante os primeiros cinco dias pós-parto, a mulher sofre a denominada apojadura, que é o enchimento dos ductos lactíferos de leite, e sua fluidificação. Esse leite, quando em excesso, pode entrar em estase e causar um mal conhecido pelas mulheres como "leite empedrado" ${ }^{20}$.

A ocorrência da estase mamária pode ser tratada de forma precoce com técnicas simples como a massagem e a mamada em livre demanda, contudo, quando o problema não é tratado adequadamente pode evoluir para complicações como o ingurgitamento mamário ou a mastite puerpera ${ }^{21}$. Por esse motivo, torna-se imprescindível que a mulher seja instruída sobre técnicas de massagem para a mama e orientada para não controlar o tempo de sucção do bebê, nem as horas da mamada ${ }^{20,22}$.

Durante o puerpério, os cuidados com o bebê também são essenciais, muitas mães, principalmente as primíparas, ainda não têm segurança para prestar os cuidados adequados com o RN, destacando-se a insegurança para a prevenção de acidentes. Segundo a literatura, os principais acidentes com o RN até o primeiro ano de vida são as queimaduras, seguido de sufocamentos, quedas, intoxicações e afogamentos ${ }^{23}$. Diante disso, faz-se necessário que os serviços de assistência pré-natal orientem constantemente pais e familiares a respeito dos acidentes domésticos na infância e como preveni-los ${ }^{23}$.

Em relação à higiene do coto umbilical, um número significativo de mães desconhece os procedimentos corretos para sua limpeza. O coto umbilical do bebê merece bastante atenção dos pais, principalmente nos primeiros dez dias de vida, uma vez que pode ser uma porta para infecções, como a onfalite e o tétano neonatal ${ }^{17}$.

Estudos orientam que o coto deve ser mantido sempre limpo e seco com álcool a $70 \%$ até a sua queda e que costumes antigos como faixas, borra de café, moedas e outros objetos devem ser descontinuados, pois trazem 
contaminação ao local, podendo iniciar um processo infeccioso $^{24-25}$. Em muitos casos, as mães até sabem quais os cuidados necessários para a limpeza do coto do bebê, porém a cultura dos antepassados ainda prevalece ${ }^{25}$. Por esse motivo, é de extrema relevância a realização da visita puerperal pelo enfermeiro, a fim de prestar orientações sobre os cuidados in locu . $^{18}$.

O desconhecimento da chupeta como vetor para afecções no neonato foi referido por 19,7\% das puérperas entrevistadas. $\mathrm{O}$ uso da chupeta é muitas vezes estimulado pelos pais, frente ao choro infantil, com o objetivo de confortar a criança inquieta. Todavia, a sua utilização é responsável por $83,5 \%$ das anomalias de oclusão, como deformação da mandíbula, mordidas anormais e malformação dentária ${ }^{26}$.

Um estudo realizado com as informações contidas nos prontuários de 335 famílias assistidas pela fonoaudiologia em Fortaleza - CE evidenciou que a chupeta é responsável pelo desenvolvimento de distúrbios orofaciais como o mau posicionamento dentário e a presença de afecções da infância como a cândida oral ou monilíase, com desconforto para o neonato e causando o choro e a falta de alimentação ${ }^{27}$.

Após a atividade educativa, foi repassado um novo questionário às mulheres, em que houve $100 \%$ de acertos, pois, de acordo com as participantes, a atividade esclareceu as dúvidas, de maneira lúdica e com material simples, e relembrou pontos importantes sobre os cuidados com a mãe e com o bebê, proporcionando a aquisição de novos conhecimentos.

As mães relataram que essas sessões deveriam ser realizadas de maneira periódica, por fornecem instruções e aprendizados proveitosos. As sessões educativas devem estar sempre presentes, pois, há interesse conjunto dos profissionais de saúde em promover ações educativas para as puérperas e prevenir futuras intercorrências ${ }^{28}$. No entanto, ao se realizar tais atividades, os profissionais devem identificar as necessidades e o nível de conhecimento dos indivíduos quanto aquele assunto, abrangendo também a família ${ }^{29}$.

Diante desse contexto, é importante que os profissionais de saúde, sobretudo os enfermeiros, orientem constantemente as mulheres e seus familiares em todos os ciclos da gestação, sendo necessário o desenvolvimen- to de ações lúdicas e de fácil compreensão, permitindo a participação efetiva e a formação ou o fortalecimento do vínculo de confiança entre todos os envolvidos nesse processo.

\section{CONCLUSÃO}

Diante do exposto, percebeu-se que é essencial a prática de sessões educativas para fortalecer o cuidado integral do binômio mãe-filho. As mulheres devem ser orientadas constantemente, durante e após a gravidez, a fim de evitar agravos para sua saúde e a do bebê. O profissional de enfermagem deve atuar como agente facilitador e orientador junto às puérperas, principalmente as primíparas e seus familiares, relacionado às principais questões que envolvem o período puerperal.

Neste estudo, observou-se que as puérperas ainda possuem concepções errôneas relacionadas ao aleitamento materno e aos cuidados gerais com o RN. Nesse sentido, deve ser dada ênfase maior na orientação dos cuidados com as mamas e a amamentação, pois foi evidenciado que, embora grande parte das mulheres conheça os benefícios do leite materno, muitas ainda têm práticas errôneas e empíricas na amamentação.

Percebeu-se também que a chupeta ainda é bastante utilizada como agente tranquilizador para o bebê, fato esse que deve ser combatido, uma vez que atua como transmissor de afecções e provoca o desenvolvimento de problemas de má oclusão dentária.

As mães devem também receber mais orientações sobre os cuidados com o coto umbilical, haja vista que foi uma deficiência encontrada, porque, embora todas referiram sentirem-se seguras para cuidar do coto umbilical do bebê, boa parte relatou não saber do uso do álcool a $70 \%$ como cuidado principal. Por fim, a prevenção de acidentes com a criança no primeiro ano de vida merece atenção, visto que muitos bebês ainda sofrem acidentes domésticos, principalmente relacionados a queimaduras pela água do banho ou asfixia pelo excesso de panos e cobertores no berço.

Diante da problemática evidenciada, torna-se necessária a prática constante de educação em saúde às gestantes e puérperas, tanto na assistência pré-natal como na Unidade de Alojamento Conjunto, associado à distribuição de material educativo de fácil compreensão. 
O enfermeiro deve atuar como uma fonte de orientação, para proporcionar informações a respeito de práticas seguras para o cuidado com a mãe e com o RN.

\section{REFERÊNCIAS}

1. Cassiano ACM, Carlucci SEM, Gomes CF, Bennemann. Saúde materno infantil no Brasil: evolução e programas desenvolvidos pelo Ministério da Saúde. Rev Serv Públ. 2014;65(2):227-44.

2. Brasil. Ministério da Saúde. Secretaria de Atenção à Saúde. Área Temática de Saúde da Criança e Aleitamento Materno. Gestões e gestores de políticas públicas de atenção à saúde da criança: 70 anos de história. Brasília: Ministério da Saúde, 2011.

3. Mendes, PDG, Carvalho Filha FS, Silva RSA, Vilanova JM, Silva FL. O papel educativo e assistencial de enfermeiros durante o ciclo-gravídico-puerperal: a percepção de puérperas. R Interd. 2016;9(3):49-56.

4. Dodou HD, Oliveira TODA, Oriá MOB, Rodrigues DP, Pinheiro PNC, Luna IT. Educational practices of nursing in the puerperium: social representations of puerperal mothers. Rev Bras Enferm. 2017;70(6):1250-8.

5. Paula Júnior JD, Lucas ES, Cunha LMC, Machado MGM, Pedrosa RL. Perfil da mortalidade neonatal no município de Ubá/MG, Brasil (2008-2010). Rev Bras Pesq Saúde. 2016;18(3):24-31.

6. Silva RM, Sousa AKA, Abreu RMSX, Silva RA, Farias MCAD. Atuação da enfermagem em alojamento conjunto: percepção de puérperas. REBES. 2015;5(3):3544.

7. Faria AC, Magalhães L, Zerbetto SR. Implementação do Alojamento Conjunto: dificuldades enfrentadas na percepção de uma equipe de enfermagem. Rev Eletr Enf. 2010;12(4):669-77.

8. Glashan QR. Manual de cuidados do recém-nascido. [S.L] 2008.

9. Levy L, Bértolo H. Manual de Aleitamento Materno. Editora: UNICEF, 2012. Disponível em: https://www. unicef.pt/docs/manual_aleitamento_2012.pdf

10. Menezes $\mathrm{CH}$. Vale à pena Crescer em Segurança. 3. ed. Editora: Associação para a Promoção da Segurança Infantil (APSI), 2003.

11. Von Seehausen MP, Oliveira MIC, Boccolini CS. Fatores associados ao aleitamento cruzado. Ciênc Saúde Colet. 2017;22(5):1673-82.

12. Broilo MC, Louzada ML, Drachler ML, Stenzel LM, Vitolo MR. Maternal perception and attitudes regarding healthcare professionals' guidelines on feeding practices in the child's first year of life. J Pediatr. 2013;89(5):485-91.

13. Lamounier JA, Moulin ZS, Xavier CC. Recommendations for breastfeeding during maternal infections. J Pediatr. 2004;80(suppl 5):181-8.

14. Boccolini CS, Boccolini PMM, Carvalho ML, Oliveira MIC. Exclusive breastfeeding and diarrhea hospitalization patterns between 1999 and 2008 in Brazilian State Capitals. Ciên Saúde Colet. 2012;17(7):185763.

15. Giugliani, ERJ. O aleitamento materno na prática clínica. J Pediatr. 2000;76(Suppl 3):238-52.

16. Costa R, Salomão A, Araújo C, Bezerra K. Dificuldades encontradas pelas mães ao amamentar em uma unidade de referência em atenção primária. DêCiência em Foco. 2017;1(1):48-63.

17. Carvalho MS, Santana MDA, Oliveira SJGS. Educação em saúde durante o pré-natal com foco nos cuidados relacionados ao recém-nascido. Cadernos de Graduação. 2016;3(3):195-208.

18. Xavier ACA, Jesus MGR, Pereira AS, Santos KA, Ferreira DAS, Sales SNV. Cuidados com o recém-nascido. RITEC. 2015;1(1):168-72, 2015.

19. Chemello RML, Giugliani ERJ, Bonamigo RR, Bauer VS, Cecconi MCP, Zubaran GM. Breastfeeding and mucosal and cutaneous colonization by Staphylococcus aureus in atopic children. An Bras Dermatol. 2011;86(3):435-9.

20. Barros SMO. Enfermagem Obstétrica e Ginecológica: guia para prática assistencial. 2ed. São Paulo: Roca, 
2009.

21. Rocha SK, Ravelli APX. Práticas culturais de puérperas no aleitamento materno: problemas mamários. Rev Triang. 2014;7(1):140-57, 2014.

22. Zorzi NT, Bonilha ANL. Práticas utilizadas pelas puérperas nos problemas mamários. Rev Bras Enferm. 2006;59(4):521-6.

23. Barcelos RS, Santos IS, Matijasevich A, Barros AJ, Barros FC, França GV, Silva VL. Falls, cuts and burns in children 0-4 years of age: 2004 Pelotas (Brazil) birth cohort. Cad Saúde Pública. 2017;33(2):e00139115.

24. Miranda JOF, Santos DV, Camargo CL, Rosa DOS, Nascimento Sobrinho CL, Mussi FC. Evidence for umbilical stump care practices: integrative review. J Nurs UFPE on line. 2016;10(Supl 2):821-9.

25. Almeida JM, Linhares EF, Dias JAA, Lôbo MP, Reis ASF, Nery PIG. Educational practice in the care for umbilical cord stump: experience report. J Nurs UFPE on line. 2016;10(Supl 5):4383-8.

26. Carrascoza KC, Possobon RF, Ambrosano GMB, Costa Júnior AL, Moraes ABA. Determinants of pacifier use among infants attending an interdisciplinar breastfeeding promotion program. Rev CEFAC. 2014;16(2):582-91.

27. Antunes DK. Perfil fonoaudiológico da comunidade do Dendê: perspectiva para ações futuras. Rev Soc Bras Fonaudiol. 2010;15(2):264-69.

28. Frederico P, Fonseca LMM, Nicodemo AMC. Atividade educativa no alojamento conjunto: relato de experiência. Rev Latino-Am Enferm. 2000;8(4):38-44.

29. Siqueira FPC, Santos BA. Livre demanda e sinais de fome do neonato: percepção de nutrizes e profissionais da saúde. Saúde e Pesquisa. 2017;10(2):233-41.

Recebido em: 27/03/2018

Aceito em: 08/08/2018 